J. Asiat. Soc. Bangladesh, Sci. 39(1): 53-60, June 2013

\title{
PHYSICO-CHEMICAL CHARACTERIZATION OF SILT PREPARED FROM BIJOYPUR SOIL
}

\author{
T. S. A. ISLAM ${ }^{1}$, Y. ZAKER, M. A. HOSSAIN AND M. S. ISLAM \\ Department of Chemistry, University of Dhaka \\ Dhaka-1000, Bangladesh
}

\begin{abstract}
Silt obtained from fractionated Bijoypur soil based on particle size $(53 \sim 140 \mu \mathrm{m})$ was characterized by SEM (Scanning electron microscopy), LIBS (Laser induced breakdown spectroscopy), XRD (X-Ray diffraction) and FT-IR (Fourier transform infra-red spectroscopy). $\mathrm{pH}_{\mathrm{zpc}}$ (Zero point charge $\mathrm{pH}$ ) of silt was also determined by titrimetric method. The scanning electron micrograph of silt was taken in two different magnifications. Micrographs show that the surface of silt is slightly homogenic in nature and the particle size varied between 50 and $100 \mu \mathrm{m}$. Elemental analysis of silt was performed by LIBS. According to this $\mathrm{Fe}, \mathrm{Si}, \mathrm{Ti}, \mathrm{Cu}, \mathrm{Zn}$ and $\mathrm{Na}$ are present in silt. XRD analysis indicates that silt fraction of Bijoypur soil is closely similar to kaolinite but it contains significant proportion of quartz. FT-IR analysis shows the presence of $\mathrm{Zn}=\mathrm{O}$, O$\mathrm{H}, \mathrm{Al}-\mathrm{O}-\mathrm{Si}, \mathrm{Fe}-\mathrm{O}, \mathrm{Al}-\mathrm{OH}$ and $\mathrm{Si}-\mathrm{O}$ bonds. The $\mathrm{pH}_{\mathrm{zpc}}$ value of silt was obtained as $6.39 \pm$ 0.02 indicating neutrality of the surface.
\end{abstract}

Key words: Silt, Characterization, SEM, LIBS, FT-IR, XRD, $\mathrm{pH}_{\mathrm{zpc}}$

\section{Introduction}

Clay minerals are generally defined as very fine grained, natural, earthy material aggregates consisting essentially of the hydrous silicate of alumina. This hydrous silicate becomes hard when dried or fired. Sometime the aluminum silicate contains variable amounts of iron, magnesium, alkali metals, alkaline earths and other cations having structural similarity to the micas and form flat hexagonal sheets (Sjöberg et al.1990). Clay minerals can be fractionated to different categories (Day 1965, Gee and Bauder 1986 and Schmidt et al. 1999). Based on particle size, three different fractions as sand, silt and clay can be obtained from soil. Silt is soil or rock of a grain size between sand and clay. Silt may occur as a soil or as suspended sediment (also known as suspended load) in surface water. It may also exist as soil deposited at the bottom of a water body. Silt is created by a variety of physical processes capable of splitting the generally sandsized quartz crystals of primary rocks by exploiting deficiencies in their lattice (Moss and Green 1975). These involve chemical weathering of rock and regolith, and a number of physical weathering processes such as frost shattering and haloclasty (Goudie and Viles 1995). The main process is abrasion through transport, including fluvial comminution, aeolian attrition and glacial grinding (Wright et al. 1998). Mineralogically, silt is

\footnotetext{
${ }^{1}$ Corresponding author: E-mail: tajmeri@du.ac.bd
} 
composed mainly of quartz and feldspar. Sedimentary rock composed mainly of silt is known as siltstone. Silt is easily transported in water or other liquids and is fine enough to be carried long distances by air as 'dust'. Silt and clay contribute to turbidity in water. Silt is transported by streams or by water currents in the ocean. Silt deposited by annual floods along the Nile River, created the rich and fertile soil that sustained the Ancient Egyptian civilization. Silt obtained through the fractionation of soil can be characterized by several analytical techniques e.g. elemental analysis, surface charge / surface $\mathrm{pH}$, phase, molecular analysis.

The objective of the present investigation was to characterize the surface of silt by SEM and $\mathrm{pH}_{\mathrm{zpc}}$, to analyze different elements present by LIBS, molecular bonding analysis by FT-IR and phase analysis by XRD.

\section{Materials and Methods}

Bijoypur soil was characterized by Miran et al. (2008); investigation was carried out for soil sample dried at $120^{\circ} \mathrm{C}$ and calcined at $500^{\circ} \mathrm{C}$ and characterized by FT-IR, TGA/DTA and XRD. Bijoypur clay fraction was characterized by Zaker et al. (2013); by SEM, LIBS, FT-IR, XRD and $\mathrm{pH}_{\text {zpc }}$.

Silt was prepared from the fractionation of Bijoypur (Netrokona) soil. Different methods are available for the fractionation of soil samples (Day 1965; Gee and Bauder 1986; Schmidt et al. 1999). But in the present investigation, Hydrometer method (Day 1965) was used.

A small portion of fractionated silt was separately taken in a Scanning Electron Microscope (SEM) sample holder and made it platinum coated using a Pt-coated auto system (JFC-1600, JEOL, Japan). Platinum coated clay was placed in the SEM sample chamber and SEM picture was taken at $20 \mathrm{kV}$ with 2000 and 30,000 magnification and presented in Fig.1.
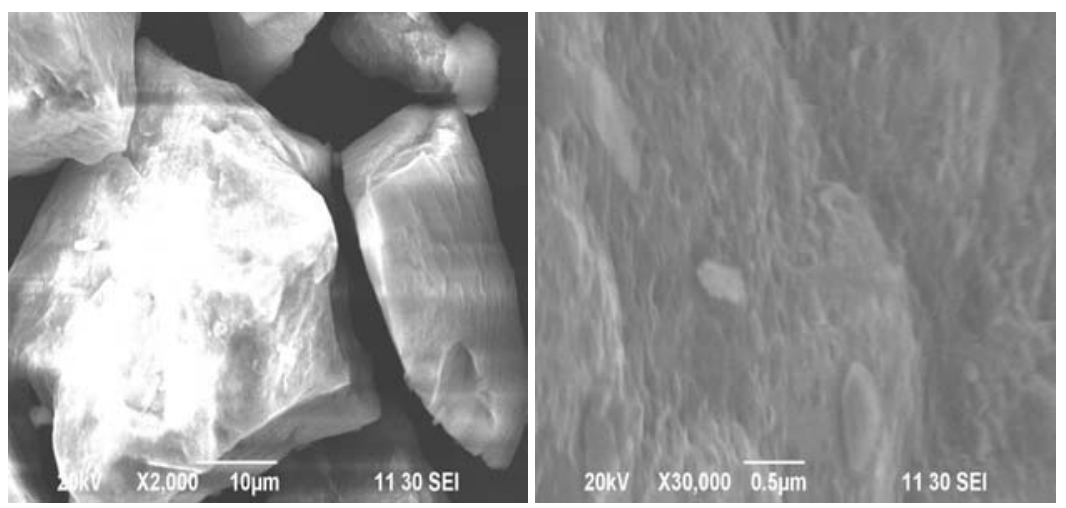

Fig. 1. SEM micrograph of silt with 2000 and 30,000 magnifications. 
The prepared silt was air dried for several days. Then these were crushed and ground for making powder. The powder samples were then reserved in plastic jar. For LIBS technique, about 0.5-1.0 g silt was mixed with 1-2 drops of glue and small pellet was made. This was air dried before use. LIBS spectroscopy can be produced from high intensity laser pulse interacting with the sample producing a plasma plume that evolves with time from the point of impact of the incident laser pulse. The laser pulse usually lasts for 5 to $20 \mathrm{~ns}$. LIBS spectra were taken in the spectral range of 200-900 nm for silt fraction using two gratings, One of them was $2400 \mathrm{ruling} / \mathrm{mm}$ grating blazed at $240 \mathrm{~nm}$ (for 200-350 nm) and the other was a grating with $600 \mathrm{ruling} / \mathrm{mm}$ blazed at $500 \mathrm{~nm}$ (for 350-900 nm). The characteristic emission lines with respect to NIST atomic spectral reference data-2010 for corresponding elements with oxidation states are presented in Table 1 .

Table 1. Characteristic emission lines of elements present in silt.

\begin{tabular}{|c|c|c|c|}
\hline No & Element & $\begin{array}{l}\text { Charge } \\
\text { state* }\end{array}$ & $\begin{array}{c}\text { Characteristic emission lines (wavelength, } \mathrm{nm} \text { ) } \\
\text { for identification of the elements }\end{array}$ \\
\hline 1 & $\mathrm{Si}$ & I & $\begin{array}{l}212.357,221.062,221.643,251.437,288.170, \\
298.732\end{array}$ \\
\hline \multirow{3}{*}{2} & & I & $263.108,295.580,390.387,429.946,453.324$ \\
\hline & $\mathrm{Ti}$ & II & $\begin{array}{l}308.780,316.242,316.842,323.409,323.614, \\
326.121,334.817,337.165,338.261\end{array}$ \\
\hline & & I & $\begin{array}{l}251.612,252.417,294.747,296.659,297.286 \text {, } \\
302.029,438.249\end{array}$ \\
\hline 3 & $\mathrm{Fe}$ & II & $\begin{array}{l}227.629,234.318,238.174,273.949,274.924, \\
275.571\end{array}$ \\
\hline 4 & $\mathrm{Cu}$ & II & 766.340 \\
\hline 5 & $\mathrm{Zn}$ & II & $467.586,471.778,480.597$ \\
\hline 6 & $\mathrm{Na}$ & I & $588.884,589.487,261.173$ \\
\hline
\end{tabular}

* I and II imply neutral and singly ionized states of the atoms respectively.

FT-IR spectra of silt were taken from the Centre of Excellence, University of Dhaka. This was carried out by Shimadzu FT-IR spectrometer (IR prestige 21) equipment using potassium bromide pellet. The pellet was prepared by mixing $1.0 \mathrm{mg}$ of finely ground dry sample and $200.0 \mathrm{mg}$ of spectroscopic grade dry $\mathrm{KBr}$. The mixture was ground thoroughly in an agate mortar and pressed between a pair of special dice under a pressure of 8-9 tons using hydraulic press for 5 minutes connected with vacuum pump for removal of $\mathrm{CO}_{2}$. The spectra were recorded between $500-4000 \mathrm{~cm}^{-1}$ with $2 \mathrm{~cm}^{-1}$ resolution. Usually 10 scans were recorded. FT-IR spectrum is presented in Fig. 2 and spectral data of silt were compared with standard data for different bonds with different vibrational modes as shown in Table 2. 


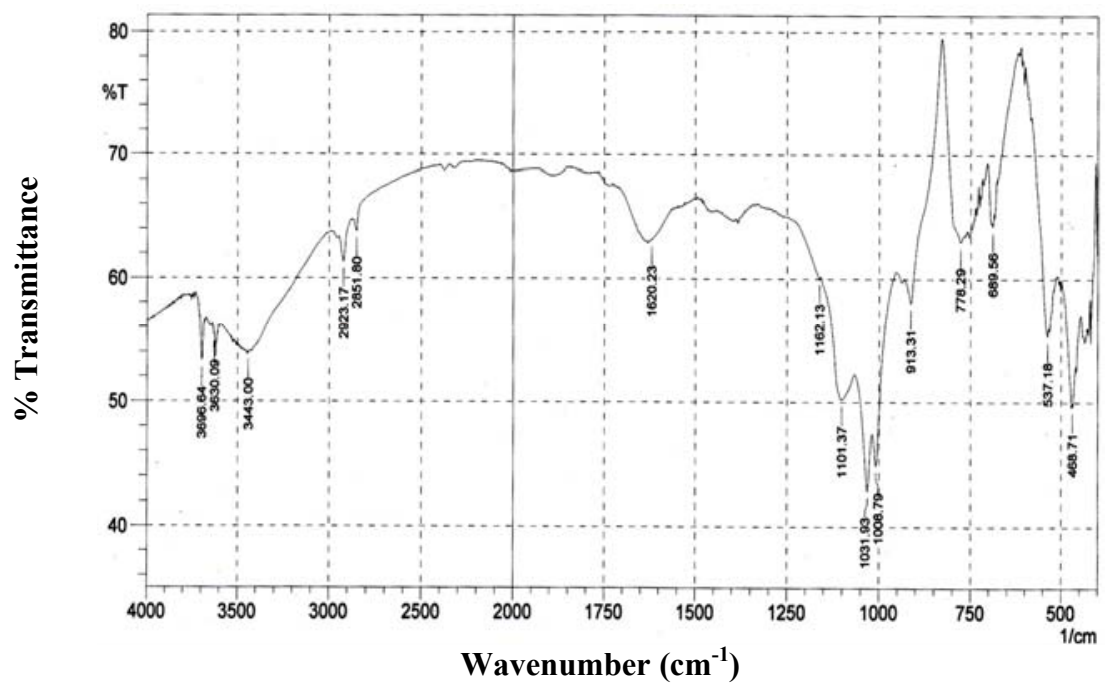

Fig. 2. FT-IR spectrum of Bijoypur silt fraction.

Table 2. FT-IR analysis for Bijoypur silt fraction.

\begin{tabular}{c|cccc}
\hline Functional group & standard & Silt & Comment \\
\hline O-H (stretching vibration) & $3710-3200$ & $3696,3630,3443$ & O-H present \\
Zn=O (plane bending) & $1650-1350$ & 1620 & $\mathrm{Zn}=$ O may present \\
Si-O (plane bending) & $1150-900$ & $1101,1031,1008,913$ & Si-O present \\
Al-OH (bending) & $900-600$ & 778,689 & Al-OH present \\
Fe-O (bending) & $460-490$ & 468 & Fe-O may present \\
Al-O-Si (skeletal vibration) & $550-450$ & 537,468 & Al-O-Si may present \\
\hline
\end{tabular}

X-ray powder pattern of silt sample was recorded with a Philips PW-1380 X-ray generator operating at $40 \mathrm{kV}$ and $30 \mathrm{~mA}$ and an XDC-700 Guinier- Hägg focusing camera using $\mathrm{Cuk}_{\alpha 1}$ radiation. An exposed time of 1 hour was used and the film was processed using commercially available developer and fixer. The d-values of the diffraction lines in the films were calculated manually and presented in Table 3. 
Table 3. X-ray data of silt along with the data from JCPDS for kaolinite, quartz, chlorite, Illite and clay fraction of Bijoypur soil.

\begin{tabular}{c|c|c|c|c|c}
\hline $\begin{array}{c}\mathrm{d} \text {-values of silt } \\
\text { fractionated from } \\
\text { Bijoypur soil, } \mathrm{A}^{\mathrm{o}}\end{array}$ & $\begin{array}{c}\mathrm{d} \text {-values of clay } \\
\text { fractionated from } \\
\text { Bijoypur soil } \\
\text { (Zaker et al. 2013) } \\
\mathrm{A}^{\mathrm{o}}\end{array}$ & $\begin{array}{c}\text { d-values of } \\
\text { Kaolinite } \\
\mathrm{A}^{\mathrm{o}}\end{array}$ & $\begin{array}{c}\text { d-values of } \\
\text { Quartz } \\
\mathrm{A}^{\mathrm{o}}\end{array}$ & $\begin{array}{c}\text { d-values of } \\
\text { Chlorite } \\
\mathrm{A}^{\mathrm{o}}\end{array}$ & $\begin{array}{c}\mathrm{d} \text {-values of } \\
\text { Illite } \\
\mathrm{A}^{\mathrm{o}}\end{array}$ \\
\hline 4.25 & 7.08 & 7.1 & 4.32 & 7.70 & 10.0 \\
3.35 & 4.25 & 4.41 & 3.38 & 4.78 & 5.02 \\
2.47 & 3.35 & 3.56 & 2.50 & 4.44 & 4.48 \\
2.28 & 2.58 & 2.55 & 2.30 & 3.50 & 4.44 \\
2.23 & 2.43 & 2.49 & 2.16 & 2.56 & 3.46 \\
2.13 & 2.28 & 2.43 & 2.01 & 2.50 & 3.34 \\
1.98 & 2.11 & 2.38 & 1.84 & 2.34 & 3.20 \\
1.82 & 1.82 & 2.33 & 1.70 & 1.98 & 2.99 \\
1.68 & & 2.20 & 1.57 & 1.66 & 2.56 \\
1.55 & & 1.98 & & & 2.00 \\
1.45 & & 1.79 & & & 1.49 \\
1.39 & & 1.67 & & \\
1.38 & & 1.66 & & \\
1.29 & & 1.54 & & \\
1.26 & & 1.49 & & \\
\hline
\end{tabular}

The $\mathrm{pH}$ of silt surface at zero point charge $\left(\mathrm{pH}_{\mathrm{zpc}}\right)$ was determined by the method suggested by titrimetric process (Huang and Ostovic 1989). $0.1 \mathrm{~g}$ of silt was added to four identical portions of $40 \mathrm{~mL} 0.1 \mathrm{M} \mathrm{NaCl}$ solution of $\mathrm{pH}$ 7. The mixtures were agitated for 24 hours in thermo mechanical shaker (SWB-20, HAAKE, Fisons Ltd, Germany). Two bottles of suspension were titrated; One with $0.05 \mathrm{M} \mathrm{HCl}$ and another with $0.05 \mathrm{M} \mathrm{NaOH}$ using micro burette $( \pm 0.01 \mathrm{~mL})$. During the titration, the constant $\mathrm{pH}$ reading was taken carefully. From other two bottles, the supernatants after filtration were titrated similarly; one with $0.05 \mathrm{M} \mathrm{HCl}$ and another with $0.05 \mathrm{M} \mathrm{NaOH}$ as described above. From above titration four curves were obtained for the plot of $\mathrm{pH}$ versus volume of acid or alkali. Using these plots in a same scaled single graph differences in volume $(\Delta \mathrm{V})$ at constant $\mathrm{pH}$ for suspension and supernatants were estimated. Using these data, $\Delta \mathrm{V}$ versus $\mathrm{pH}$ plot was obtained for $0.1 \mathrm{M} \mathrm{NaCl}$. Similarly another plot was obtained for $0.01 \mathrm{M} \mathrm{NaCl}$ solution. These two plots intersect at a point defined as surface zero point charge $\mathrm{pH}\left(\mathrm{pH}_{\mathrm{zpc}}\right)$ of silt (Fig. 3). 


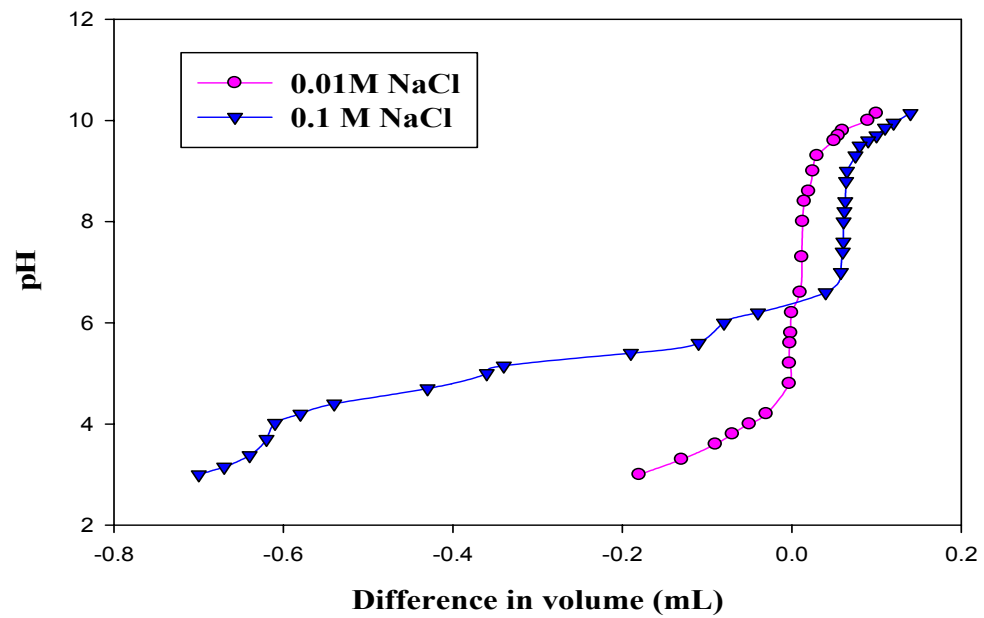

Fig. 3. Net titration curves for silt in presence of different concentrations of $\mathrm{NaCl}$. The curves intersect at the $\mathrm{pH}_{\mathrm{zpc}}$

\section{Results and Discussion}

Silt particles fractionated from Bijoypur soil presented in Fig.1 show the SEM micrograph of silt by two different magnifications such as 2,000 and 30,000. It indicates that the fractionated silt's particle size and shapes are not uniform. There were many pores and cavities in surface which make the surface to act as a moderate adsorbent (Gurses et al. 2006). SEM micrographs of clay fraction of Bijoypur soil (Zaker et al. 2013) also indicated strong adsorbent properties in surface. In comparison to clay, silt has fewer pores and cavities on surfaces. Particle size of silt varied between 50 to $100 \mu \mathrm{m}$ which is higher than the particle size of clay.

LIBS were used to analyze the presence of element in the silt. Table 1 shows the list of elements present in the silt sample (NIST Atomic Spectra Ref. Data 2010). Comparing with LIBS spectra of clay fraction of Bijoypur soil, it was observed that there were lower number of emission lines for identification of elements detected and lines for Sn and Co are absent here (Zaker et al. 2013).

Different vibrational modes of bonding of silt were investigated using FT-IR spectroscopy. Fig. 2 shows the FT-IR spectrum of fractionated silt. Respective vibrational mode for different functional groups analyzed with standard FT-IR data (Xu and Axe 2005 and Ozcan and Ozcan 2004) is presented in Table 2. FT-IR analysis of silt and clay of Bijoypur soil when compared with that of Zaker et al. (2013) no differences were found. 
X-Ray powder diffraction (XRD) method was also used to compare the silt with several clay minerals such as kaolinite, illite, quartz and chlorite. The d- values of XRD pattern of silt were estimated and compared with standard values of clay minerals supplied by JCPDS (Joint Committee on Powder Diffraction Standards). The values are shown in Table 3. Comparing the d-values, it can be concluded that the silt is mainly quartz, (Silicon oxide, $\mathrm{SiO}_{2}$ ) containing small amount of Kaolinite type of mineral (Aluminum silicate hydroxide, $\mathrm{Al}_{2} \mathrm{Si}_{2} \mathrm{O}_{5}(\mathrm{OH})_{4}$, trace amount of Chlorite, (Sodium Aluminum Silicate Hydroxide Hydrate, $\mathrm{Na}_{0.5} \mathrm{Al}_{6}(\mathrm{Si}, \mathrm{Al})_{8} \mathrm{O}_{20}(\mathrm{OH})_{10} \cdot \mathrm{H}_{2} \mathrm{O}$ ) and Illite, (Potassium Aluminum Silicate Hydroxide, $\left(\mathrm{K}, \mathrm{H}_{3} \mathrm{O}\right) \mathrm{Al}_{2} \mathrm{Si}_{3} \mathrm{AlO}_{10}(\mathrm{OH})_{2}$. d-values of fractionated silt when compared with fractionated clay, it was observed that a large number of d-values are obtained in case of silt. Quantitatively the values are not same as d-values of clay (Zaker et al. 2013).

The $\mathrm{pH}$ of the zero point charge is the $\mathrm{pH}$ of the solution at which the charges on the surface (-ve or $+\mathrm{ve}$ ) are balanced by the addition of acid or alkali. In Fig. 3 the point of intersection of two curves is the $\mathrm{pH}_{\mathrm{zpc}}$ of silt and it was estimated as $6.39 \pm 0.02$. The value is almost equal to the $\mathrm{pH}_{\mathrm{zpc}}$ of clay $(6.40 \pm 0.02)$. The $\mathrm{pH}_{\mathrm{zpc}}$ of silt indicated that the surface of silt acts as a positive charge at $6.39 \pm 0.02$ and below, whereas negative charge at $\mathrm{pH}$ is higher than $6.39 \pm 0.02$. These results indicate that surface of silt fraction is almost neutral suggesting that the cationic adsorbate would favor basic medium and anionic adsorbate would favor acidic medium.

It can be concluded that the particle size and shapes of silt are not uniform and the sizes are in between 50 to $100 \mu \mathrm{m}$. Many metals bonded with oxygen are present in silt. XRD lines and d-values indicate that silt fraction resembles more to quartz than kaolinite.

\section{References}

Day, P. R. 1965. Particle formation and particle size analysis, In: Methods of Soil Analysis, Part$\boldsymbol{I}$ (eds. CA Black, DD Evans, JL White, LE Ensminger and FE Clark). Agronomy Monograph. 545-567.

Gee, G. W. and J. W. Bauder. 1986. Particle-size Analysis. In: A. Klute (Editor), Methods of Soil Analysis. Part I (2nd ed.) Agronomy. 9: 383-399.

Goudie, A . S. and H. A. Viles. 1995. The nature and pattern of debris liberated by salt weathering: a laboratory study. Earth Surface Processes and Landforms. 9: 95-98.

Gurses, A., C. Dogar, M. Yalcin, M. Akyildiz, R. Bayrak and S. Karaca. 2006. The adsorption kinetics of the cationic dye, MB, onto clay. J. Hazardous Materials. B131: 217-228.

Huang, C.P. and Ostovic. 1989. Removal of Cd(II) by activated carbon adsorption. J. Env. Div. ASCE. 104: 863-878.

Miran, M. S., M. Y. A. Mollah, A. Hussain and M. M. Rahman. 2008. A multi-technique characterization of Bijoypur clay. Bangladesh J. Sci. Res. 21(1,2): 15-22.

Moss, A. J. and P. Green. 1975. Sand and silt grains: Predetermination of their formation and properties by microfractures in quartz. Australian J. Earth Sci. 22 (4): 485-495.

NIST Atomic Spectra Database. 2010. http://physics.nist_gov/physrefdata/ASD/ lines_form.html. 
Ozcan, A. S. and A. Ozcan. 2004. Adsorption of acid dyes from aqueous solutions onto acidactivated bentonite. J. Colloid Interface Sci. 276: 39-46.

Schmidt, M. W. I., C. Rumpel and I. Kogel-Knabner. 1999. Particle size fractionation of soil containing coal and combustion particles. European J. Soil Sci. 50: 515-522.

Sjöberg, M., L. Bergström, A. Larsson and E. Sjöstrom. 1990. The Effect of Polymer and Surfactant Adsorption, on the Colloidal Stability and Rheology of Kaolin Dispersions, Elsevier. 159: 197-208.

Wright, J. S., B. J. Smithand and W. B. Whalley. 1998. Mechanisms of Loess-sized Quartz Silt Production and their Relative Effectiveness: Laboratory Simulations. Geomorphology. 23: $15-34$.

Xu, Y. and L. Axe. 2005. Synthesis and Characterization of Iron Oxide-Coated Silica and Its Effect on Metal Adsorption. J. Colloid and Interface Sci. 282(1): 11-19.

Zaker, Y., M. S. Islam, M. A. Hossain and T. S. A. Islam. 2013. Physico-Chemical Characterization of Clay Fractionated from Bijoypur Soil. Bangladesh J. Agri. Env. 9(1): in press. 